\title{
Discovering genetic diversity of Changmaogu, a rice landrace, for conservation and rural development
}

\author{
Liu He, ${ }^{1,2}$ Yingjie Song, ${ }^{1}$ Xiufang Liu, ${ }^{1,2}$ Qi Kang, ${ }^{1}$ Chunlin Long ${ }^{1-3}$ \\ ${ }^{1}$ Key Laboratory of Ecology and Environment in Minority Areas, Minzu University of China, National \\ Ethnic Affairs Commission; ${ }^{2}$ College of Life and Environmental Sciences, Minzu University of China; \\ ${ }^{3}$ Key Laboratory of Ethnomedicine, Minzu University of China, Ministry of Education, Beijing, China
}

\section{Highlights}

- Changmaogu, a very rare and endangered rice landrace cultivated in a very limited area by Lama people, has more abundant genetic diversity than the three compared cultivars-Hejing 16, Nipponbare and Hongxiangmi, which enables it to adapt to changing environmental conditions, ensures local food supply and agricultural economic development, and makes it an effective supplement to the rice gene pool.

- The result of UPGMA clustering analysis based on genetic distance led to the formation of three clusters, which Changmaogu had further genetic distance compared with hybrid rice Hejing 16 and rice parents Nipponbare, further revealing the utilization potential of Changmaogu in crop breeding.

- The genetic diversity of Changmaogu and Hongxiangmi was compared to reveal the important position of Changmaogu in the protection of landrace, and to explore the potential impact of commercial activities on the genetic diversity of landrace.

- According to the case of Changmaogu, this paper puts forward reasonable and effective strategies for the protection, which can be derived and applied to the protection of other landraces.

Correspondence: Chunlin Long, College of Life and Environmental Sciences, Minzu University of China; Key Laboratory of Ecology and Environment in Minority Areas, Minzu University of China, National Ethnic Affairs Commission, China; Key Laboratory of Ethnomedicine, Minzu University of China, Ministry of Education, Beijing 100081, China.

E-mail: long.chunlin@muc.edu.cn

Key words: Changmaogu rice landrace; SSR markers; genetic diversity; conservation strategy; Lama people.

Acknowledgements and funding: we are grateful to the local Lama people in Lanping who shared their valuable traditional knowledge about Changmaogu. The seeds of Changmaogu were provided by Nujiang Lanzhiyun Agricultural Comprehensive Development Co., Ltd. This research was funded by the National Nature Science Foundation of China $(31761143001,31870316)$, the Biodiversity Survey and Assessment Project of the Ministry of Ecology and Environment of China (2019HJ2096001006), and the Minzu University of China (2020MDJC03, URTP2021110075).

Received for publication: 14 March 2021.

Revision received: 5 July 2021.

Accepted for publication: 18 July 2021.

(C) Copyright: the Author(s), 2021

Licensee PAGEPress, Italy

Italian Journal of Agronomy 2021; 16:1870

doi:10.4081/ija.2021.1870

This article is distributed under the terms of the Creative Commons Attribution Noncommercial License (by-nc 4.0) which permits any noncommercial use, distribution, and reproduction in any medium, provided the original author(s) and source are credited.

\begin{abstract}
Changmaogu is a very rare and endangered rice landrace cultivated in a very limited area by Lama people, a branch of Bai ethnic group in Lanping County, Yunnan, China. No study on this precious landrace had been reported. This study was intended to explore the genetic diversity so as to develop strategy for conserving Changmaogu. The Changmaogu samples were compared with other three varieties (Hejing 16, Nipponbare and Hongxiangmi), using 24 pairs of SSR markers. Among all varieties, Changmaogu showed the richest genetic diversity. Cluster analysis also showed that Changmaogu can be distinguished in the genetic distance of 0.68 . These data suggested that landrace is of great significance for the selection of rice varieties under the harsh environment and the acquisition of parents in the breeding work. The high altitude, low temperature and complex microbial community may be the important factors of genetic diversity in Changmaogu. The influence of 'agriculture-processing-marketing' mode of landraces should be continuously tracked. The strategy for conservation and sustainable development of Changmaogu was proposed in the present paper.
\end{abstract}

\section{Introduction}

Landrace, also known as traditional variety or local variety, referring to the traditional genetic resources of animals and plants that are domesticated by local people in a certain area, can adapt to the unique natural and cultural environment (Camacho-Villa et al., 2005; Agriculture Commission on Genetic Resources, 2013; Sponenberg, 2014). It is selected or evolved in local environment, with a significant difference of regionality to standardized cultivar (Yang et al., 2019).

With the assistances of Bioversity International (now Alliance of Bioversity International and CIAT) and other international 
organizations, the advantages of landraces have been shown to the world (Jarvis et al., 2008; Bellon et al., 2014). Landraces can adapt to the agro-ecosystems which are marginal, specific and heterogeneous or the production conditions that are complicated and various. The wide adaptability of landraces can be used as a guarantee to resist adverse environment and other risks, so as to meet the changing market demand. The diversity of landraces can ensure farmers to cope with the challenge of environmental uncertainty, provide genetic materials for modern breeding work, enlarge the genetic basis of parental materials and meet the needs of the adaptation and evolution under the condition of global warming and changing production conditions (Lopes et al., 2015; Jarvis et al., 2016).

Due to the special and complex ecological environment and the needs of local traditional culture and habits, most ethnics who live in the mountains of southwest China prefer to grow various landraces, which makes the rich resources of landraces retained (Zeng et al., 2001; Zhang et al., 2007; Yang et al., 2018). It was reported that there were 76 upland landraces cultivated by Jinuo people and 61 highland barley landraces in the Tibetan area of northwest Yunnan have been reserved (Li et al., 2011). These landraces provide a guarantee for the local food supply, economic development and cultural preservation. There is no doubt that landrace plays an irreplaceable role in ethnic communities and poor mountainous areas in southwest China. Due to the Green Revolution and the loss of peasant labor force, the current situation of landraces is getting worse for some of them have been disappeared or are on the verge of extinction (Chen et al., 2009).

Lanping County is situated in Yunnan, southwest China, a mountainous area in the Eastern Himalayas. It is one of the main settlements of Lama people, one of the branches of Bai ethnic group. Changmaogu is a traditional rice landrace cultivated by the Lama people in Lanping County, and can adapt to the alpine mountainous climate in Yunnan (Long, 2016). The name of Changmaogu means rice with long awn in Chinese. It also be called 'lazy rice' for hardly fertilization, spraying and weeding until the harvest season. There are many japonica rice varieties cultivated in Yunnan (Zeng et al., 2000; Zhu et al., 2004). As a typical japonica cultivar, Changmaogu was planted in Lanping area by Lama people as far as the Tang Dynasty (A.D.618-907). It is of great significance to protect this landrace for the study of farming culture of Lama people. The growing period of Changmaogu is long, lasting for seven months, and the average yield is only 2250$3000 \mathrm{~kg} / \mathrm{ha}$ which is less than half that of the hybrid rice (Long, 2016). Since the Green Revolution in the 1960s, the high yield of hybrid rice has significantly impacted the cultivation and development of Changmaogu. Because of the long growing period and low yield, it has been gradually abandoned by local people, and the cultivation area has decreased a lot. Changmaogu has a deeper root system than common varieties, which may be the reason for the long growth period and low yield of it. However, the root of this form can also cause the crop to deplete less nutrient and add more organic matter to soil. The apparent deficiencies of Changmaogu can make it grow better on barren land and actually bring benefits for farmers to make sustainable use of marginally arable land. Therefore, the protection of this landrace will also contribute to the accurate revitalization of agricultural development in some areas with poor environment, so as to maintain the local food supply continuously.

In the past five years, fortunately, the local people who are devoted to protect landraces have participated in the establishment of a commercial company with the operation mode of 'agricultureprocessing-marketing' with the scientific assistance from research organizations, which has attracted more farmers to cultivate
Changmaogu for higher profits (Long, 2016). However, our survey found that the existing planting area of Changmaogu is still less than 15 hectares, which is a very dangerous signal for a crop, due to the geographical environment, traffic inconvenience and other factors. Landraces are of profound significance to the conservation of agrobiodiversity and agricultural heritage systems, poverty alleviation and rural development. However, due to the low yield, uneven distribution and relatively difficult to collect materials, there were few systematic and in-depth studies on landrace in China. At present, Changmaogu has also been approved as the brand of 'green food in Yunnan Province', which is a typical representative of landraces in China. The research on Changmaogu has not been published yet, so the general understanding of Changmaogu is lacking, which limits the effective utilization of it. It is necessary to evaluate the genetic diversity of Changmaogu, and look for the conservation and sustainable use pattern of this very endangered rice landrace, which will be beneficial to the protection of Changmaogu and other landraces.

Genetic diversity analysis at the gene level is a method that can directly detect the differences in biological DNA molecules (Hartings et al., 2008). According to different selection markers, the genetic diversity analysis can be divided into restriction fragment length polymorphism (RFLP), random amplified polymorphism DNA (RAPD), amplified fragment length polymorphism (AFLP), and simple sequence repeat (SSR) (Zhang, 2005). Among them, SSR has the following advantages including highly polymorphic at a single locus, namely abundant alleles (Morgante et al., 1993); codominance, which is conducive to the observation of heterozygosity (Morgante et al., 1993); well distributed and abundant sites, with an average of one microsatellite DNA in every 10 $\mathrm{kb}$ in eukaryotes (Williams et al., 1990); and general and conservative sequence, for which SSR primers can be used in closely related species (Schlötterer et al., 1991). Based on the above advantages, SSR markers can effectively reveal the genetic diversity (Williams et al., 1990; Li et al., 2004), especially among the populations closely related, the species with low levels of variation considered by other types of markers and the species requiring more information markers, such as wheat, rice, and other crops (He et al., 2020).

The SSR method was used in this research to analyze Changmaogu and other three cultivars of rice (Oryza sativa), one southwest China representative hybrid cultivar (Hejing 16), one main parental source variety (Nipponbare) and one landrace through long-term seed selection over 10 years (Hongxiangmi). The objectives of this study are: i) to compare the genetic diversity of Changmaogu with the others; ii) to reveal the genetic relationship between Changmaogu and the others; iii) to explore the factors affecting the genetic diversity of Changmaogu and reasonable protection methods.

\section{Materials and methods}

\section{Study sites}

Study sites cover three villages, Deqing, Xinhua and Jiulong, in Lanping Bai and Pumi Autonomous County, Nujiang Lisu Autonomous Prefecture, Northwest Yunnan, Southwest China. Lanping County $\left(26^{\circ} 35^{\prime} 43^{\prime \prime} \mathrm{N}, 99^{\circ} 19^{\prime} 12^{\prime \prime} \mathrm{E}\right)$ is situated in the Hengduan Mountains, part of eastern Himalayas, with an area of $4388 \mathrm{~km}^{2}$. The Changmaogu landrace is grown in fixed terraced fields with other rice varieties at an average altitude of $2200 \mathrm{~m}$, in the valley of the Lancang-Mekong River Watershed. The terraced 
fields of Changmaogu are upland and rainfed (Figure 1). They are located on the hillside. There are often evergreen forests on top of them. Lama people usually irrigate the fields with water from the the evergreen forests.

\section{Plant materials}

\section{Changmaogu}

The morphology of Changmaogu is shown in Figure 2. As its Chinese name' meaning suggests, it has a long awn at the end of the glume. The name of Changmaogu is unique in China. No other landraces with different names have similar morphology.

The Changmaogu seeds used in the study were randomly provided by Nujiang Lanzhiyun Agricultural Comprehensive Development Co., Ltd., after being collected from the three villages of Deqing, Xinhua and Jiulong in 2018. The disdance relationship between the three sampling sites of Changmaogu is shown in Figure 3. With the help of Nujiang Lanzhiyun Agricultural Comprehensive Development Co., Ltd., the three villages exchanged some seeds with each other regularly and systematically. In addition, the local farmers also retained the custom of keeping seeds by themselves, exchanging seeds among relatives, and using seeds as dowry during marriage.

\section{Control variety}

In order to compare the genetic relationship and genetic variation of Changmaogu, three varieties were used (Table 1). Hejing 16 was directly sampled from its breeding company, Yunnan Quchen Seed Industry Co., Ltd. Nipponbare seeds were from relevant research organisation. The samples of Hongxiangmi were selected from the purchaser who purchased Hongxiangmi from different planting field in Guigang City of southwest China. Hejing 16 is one of the common hybrid rice varieties in Northwest Yunnan. Like most hybrid rice in China, it is derived from multiple crosses of several local or Japanese landraces. There is no direct utilization of Nipponbare in Hejing 16's genealogy. Hejing 16 was compared with Changmaogu to explore whether Changmaogu has better genetic diversity supporting it to be adapted to the changing environment than the local hybrid rice. Nipponbare is mainly as a breeding line used by seed companies or research organisations in China. Nipponbare was compared with Changmaogu to explore Changmaogu's potential as a rice parent material. Hongxiangmi is a common landrace with 'agriculture-processing-marketing' mode for more than ten years in Northwest Yunnan. It was compared with Changmaogu to explore the effects of commercial activities on genetic diversity of landraces, and test the priority of Changmaogu in the protection of landraces. Except Hongxiangmi which is indica rice, the others are all japonica rice.

\section{DNA extraction and SSR analysis}

The sample sizes of each variety as showed in Table 1 were extracted and accelerated to the seedling stage in the laboratory environment. The leaves were extracted and stored in liquid nitro- gen, and then moved to $-80{ }^{\circ} \mathrm{C}$ for preservation. DNA extraction according to the steps of the efficient plant genome DNA extraction kit provided by Tiangen Biochemical Technology (Beijing) Co., LTD. These SSR loci covered 12 pairs of rice chromosomes, and two SSR loci were selected on each pair of chromosome to maximise the overall measurement of genetic diversity in the samples. 24 pairs of SSR primers which were with polymorphism in the test varieties were selected from the published reports $(\mathrm{Hu}$ et al., 2011; Cui, 2015; Dang et al., 2015; Wang et al., 2017; Khan et al., 2018) (Table 2).

DNA was amplified in a final volume of $20 \mu \mathrm{L}$, containing $14.8 \mu \mathrm{L} \mathrm{ddH}_{2} \mathrm{O}, 0.4 \mu \mathrm{L}$ dNTP, $2 \mu \mathrm{L}$ buffer, $0.3 \mu \mathrm{L}(20 \mu \mathrm{M})$

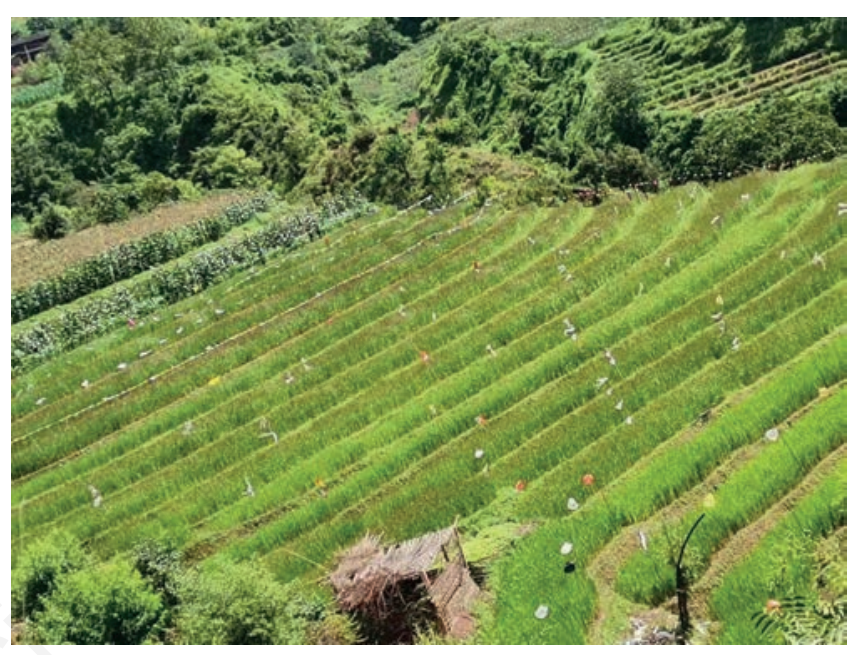

Figure 1. Terrace of Changmaogu.

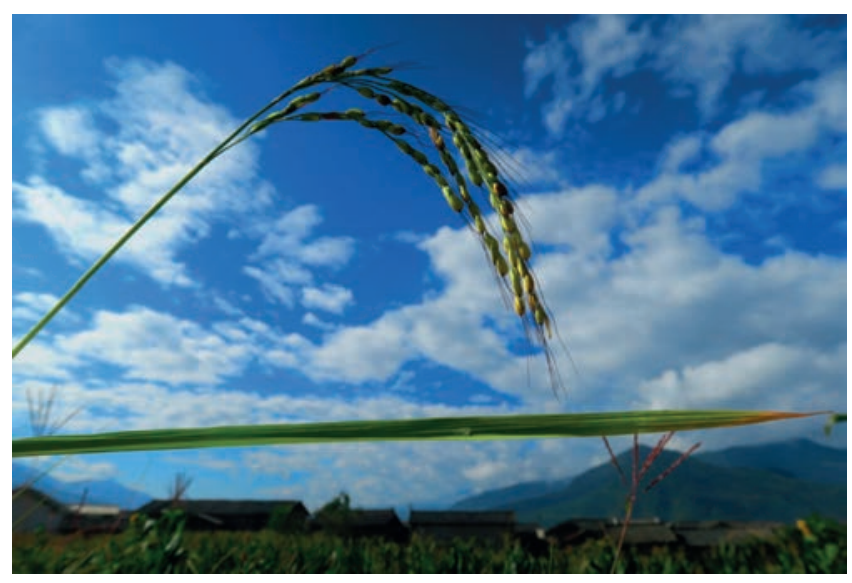

Figure 2. The morphology of Changmaogu.

Table 1. Samples for experimental analysis in this study.

\begin{tabular}{lll} 
Variety & Authorived number & Detailed information \\
$\begin{array}{ll}\text { Changmaogu } \\
\text { Hejing } 16\end{array}$ & Japonica rice, landrace \\
\hline Nipponbare & Jingyin no.153* & Japonica rice, hybrid variety \\
Hongxiangmi & & Japonica rice, one of the main parental sources of hybrid varieties \\
$*$ *hina rice data center. & Indica rice, landrace through 'agriculture-processing-marketing' mode over 10 years
\end{tabular}


upstream primer, $0.3 \mu \mathrm{L}(20 \mu \mathrm{M})$ downstream primer, $2 \mu \mathrm{L}$ DNA template and $0.2 \mu \mathrm{L}$ of the Taq polymerase. The amplification program was as follows: initial incubate at $94{ }^{\circ} \mathrm{C}$ for $5 \mathrm{~min}$ and following 35 cycles of denature at $94{ }^{\circ} \mathrm{C}$ for $30 \mathrm{~s}$, renaturation at $54{ }^{\circ} \mathrm{C}$ for $35 \mathrm{~s}$, extension at $72{ }^{\circ} \mathrm{C}$ for $40 \mathrm{~s}$, final extension at $72{ }^{\circ} \mathrm{C}$ for $3 \mathrm{~min}$.

The capillary electrophoresis method was used to detect the fragment size. The PCR products were diluted 1:10 in deionized water and $1 \mu \mathrm{L}$ of the diluted sample was added to $12 \mu \mathrm{L}$ formamide and $1 \mu \mathrm{L}$ of the internal lane standard. Capillary electrophoresis was processed by 3730xl DNA Analyzer (Applied Biosystems). The original data obtained were analyzed by Fragment (Plant) software in Genemarker (Mitchell, 2011) (Figure 4).

\section{Data analysis}

According to the data obtained, the number of alleles $(\mathrm{Na})$, the number of effective alleles $(\mathrm{Ne})$, the observation heterozygosity (Ho), the expected heterozygosity (He), the Shannon index (I) and the Nei's index were calculated by PopGen 32 (Francis et al., 2000), and the PIC value was calculated by PIC Calc (Nagy et al., 2012). The cluster analysis was performed by UPGMA using MEGA X software (Sudhir et al., 2018).

\section{Results}

\section{SSR polymorphism analysis}

In this study, a total of 24 pairs of SSR primers which were well distributed on the 12 chromosomes of rice with high polymorphism were selected (Table 2). A total of 156 alleles were detected in 128 samples of the four rice varieties. The average of alleles detected per primer pairs was 6.50 and the range was from 2 to 20 . The number of alleles detected in RM430 and RM528 was higher, 20 and 18, respectively. A total of 75.09 effective alleles were detected, with the average of 3.13 per primer pairs and the range was from 1.30 to 7.36. Shannon index (I) reflects the diversity of each SSR site. The higher the number, the richer the diversity of the site. The average I of the four varieties detected by the 24 pairs of SSR primers was 1.26 per primer pairs and the range was from 0.39 to 2.29 . Polymorphic information (PIC) represents the use value of a polymorphic locus. The higher the number, the greater

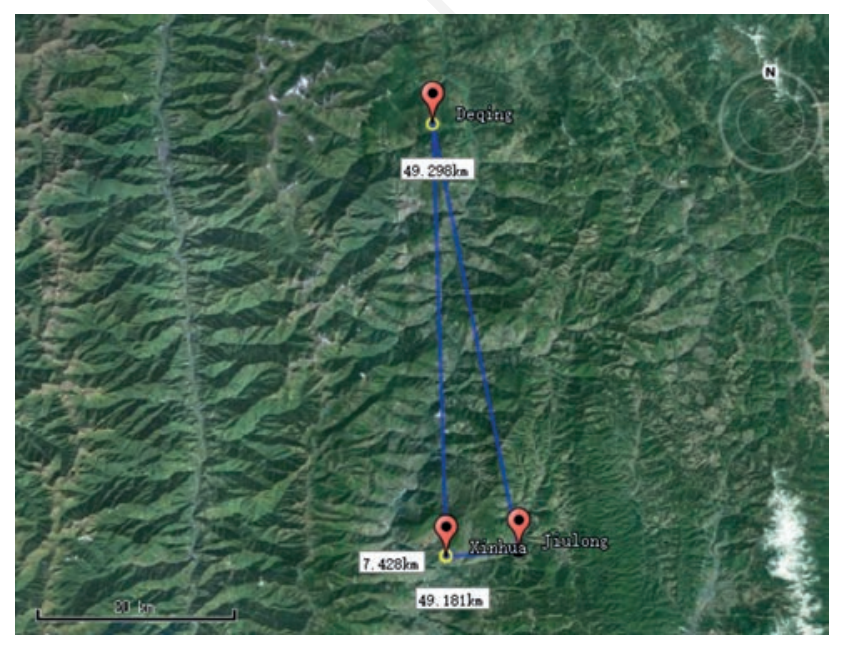

Figure 3. Sampling sites of Changmaogu. the use value. The average PIC of the four varieties detected by the 24 pairs of SSR primers was 0.58 per primer pairs and the range was from 0.20 to 0.85 .

\section{Genetic diversity analysis of populations}

To compare genetic variation within the samples, 6 indices based on alleles of each SSR marker were calculated for the four varieties. Table 3 showed the 6 major diversity parameters detected at each group. In this table, data were shown from four samples, of which 20 59 seeds were analyzed. The 6 indices of Changmaogu were all higher than the other three control varieties, with a total of 110 alleles among the 24 loci. The second-most diverse sample was Hongxiangmi, with 36 alleles. Hejing 16 and Nipponbare showed lower genetic diversity. Only 27 and 28 alleles were detected in Hejing 16 and Nipponbare, respectively.

\section{Cluster analysis}

The unweighted pair group method with arithmetic mean (UPGMA) clustering based on the genetic distance among the four varieties (Figure 5) showed that Indica rice Hongxiangmi was firstly distinguished when the genetic distance was 0.98 . The difference between Indica rice and Japonica rice was very noticeable at the DNA level, which was consistent with the previous study of Zeng et al. (2007). When the genetic distance was 0.68 , the four varieties tested can be divided into three categories: Changmaogu group was in Group II, Hejing 16 group and Nipponbare group were in Group I, Hongxiangmi group was in Group III. The results showed that the genetic relationship between Hejing 16 and Nipponbare was closer. Hejing 16 and Nipponbare could be distinguished at the genetic distance of 0.24 .

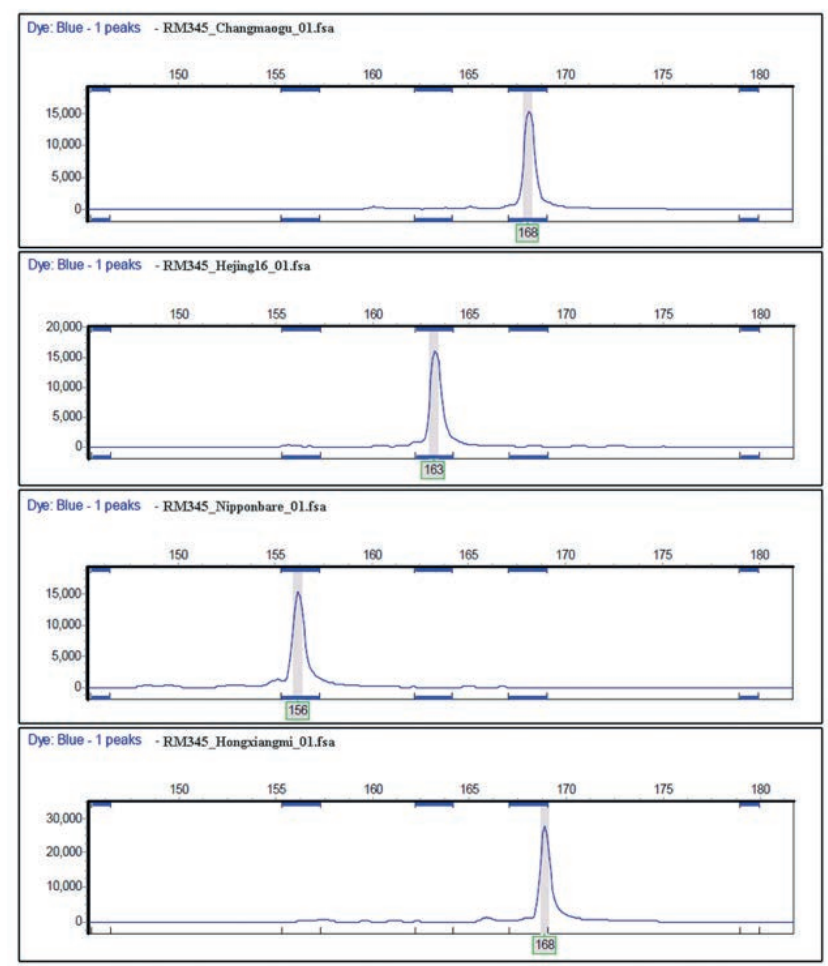

Figure 4. Capillary electropherogram obtained by RM345 primer of some samples. 


\section{Discussion}

\section{Genetic diversity of Changmaogu}

The results showed that hybrid rice Hejing 16 was not genetically monomorphic. But the genetic diversity of the hybrid rice remained at a low level, which was consistent with the result of Kobayashi et al. (2006). Changmaogu and Hongxiangmi showed much higher genetic diversity than Hejing 16. The higher genetic diversity of the landraces than those of hybrid rice Hejing 16 (Table 3) showed that landraces retained more genetic variation than hybrid cultivars. This was in the line with the research results of Yang et al. (Yang et al., 1994). Although hybrid cultivar has the advantages of high yield, its internal narrow genetic diversity can result in inadequate population control ability. Especially in the years and interannual variability of adverse environment, often after three to five years of planting period, hybrid cultivars' production will reduce because of degradation and need to be reseeded, needing higher economic cost (Xiang, 2012). Abundant alleles are the basic conditions for the species to survive in response to environmental changes (He et al., 2020). Remarkable diversity can be usually found in landraces (Brown, 1978). The diversity of farmer and natural selection in the process of agricultural activities leads to extremely stable agronomic traits within the population of landrace, causing a high degree of non-degradation adaptability to the local environment (Pusadee et al., 2009; Song et al., 2019). Therefore, for future development in some underdeveloped areas with inconvenient transportation and significant environmental changes, landrace is still an important provenance supporting local agricultural production and farmers' livelihood, as well as an important material basis for targeted rural development.

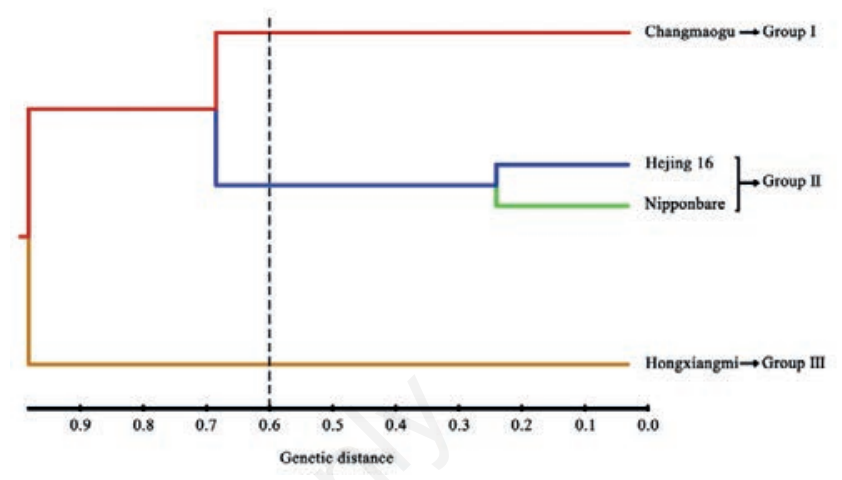

Figure 5. UPGMA clustering analysis of four varieties in three cluster groups based on genetic distance for SSR.

Table 2. Information of 24 SSR loci.

\begin{tabular}{|c|c|c|c|c|c|c|c|c|}
\hline Loci & Forward primer & Reverse primer & Chromosome & $\begin{array}{c}\text { Sample } \\
\text { size }\end{array}$ & $\begin{array}{l}\text { Number of } \\
\text { alleles } \\
(\mathrm{Na})\end{array}$ & $\begin{array}{l}\text { Numbers of } \\
\text { effective } \\
\text { alleles } \\
\text { (Ne) }\end{array}$ & $\begin{array}{l}\text { Shannon } \\
\text { index } \\
\text { (I) }\end{array}$ & $\begin{array}{l}\text { Polymorphism } \\
\text { information } \\
\text { contents } \\
\text { (PIC) }\end{array}$ \\
\hline RM490 & ATCTGCACACTGCAAACACC & AGCAAGCAGTGCTTTCAGAG & 1 & 128 & 5 & 3.15 & 1.28 & 0.63 \\
\hline RM449 & TTGGGAGGTGTTGATAAGGC & ACCACCAGCGTCTCTCTCTC & 1 & 128 & 5 & 3.23 & 1.30 & 0.64 \\
\hline RM263 & CCCAGGCTAGCTCATGAACC & GCTACGTTTGAGCTACCACG & 2 & 128 & 3 & 1.31 & 0.48 & 0.23 \\
\hline RM48 & TGTCCСACTGCTTTCAAGC & CGAGAATGAGGGACAAATAACC & 2 & 128 & 10 & 4.64 & 1.80 & 0.76 \\
\hline RM232 & CCGGTATCCTTCGATATTGC & CCGACTTTTCCTCCTGACG & 3 & 128 & 7 & 3.85 & 1.52 & 0.70 \\
\hline RM570 & GTTCTTCAACTCCCAGTGCG & TGACGATGTGGAAGAGCAAG & 3 & 128 & 5 & 2.83 & 1.18 & 0.58 \\
\hline RM5320 & CCTGAGCTGTACAAGCAAAC & CAGATTCTTGGGAGAAATCC & 4 & 128 & 3 & 1.82 & 0.71 & 0.37 \\
\hline RM1272 & TCTATGGATCTGCATGCTGG & CTGCССTGTCCTTTTAATCG & 4 & 128 & 4 & 3.06 & 1.19 & 0.61 \\
\hline RM430 & AAACAACGACGTCCCTGATC & GTGCCTCCGTGGTTATGAAC & 5 & 128 & 20 & 7.36 & 2.29 & 0.85 \\
\hline RM249 & GGCGTAAAGGTTTTGCATGT & ATGATGCCATGAAGGTCAGC & 5 & 128 & 5 & 3.57 & 1.38 & 0.67 \\
\hline RM528 & GGCATCCAATTTTACCCCTC & AAATGGAGCATGGAGGTCAC & 6 & 128 & 18 & 3.62 & 1.95 & 0.71 \\
\hline RM345 & ATTGGTAGCTCAATGCAAGC & GTGCAACAACCCCACATG & 6 & 128 & 3 & 2.30 & 0.96 & 0.50 \\
\hline RM336 & CTTACAGAGAAACGGCATCG & GCTGGTTTGTTTCAGGTTCG & 7 & 128 & 9 & 4.73 & 1.75 & 0.76 \\
\hline RM18 & TTCССТСТСATGAGCTCСAT & GAGTGCCTGGCGCTGTAC & 7 & 128 & 6 & 3.62 & 1.41 & 0.68 \\
\hline RM1019 & GTTTGAACAGTAGGACTTGT & AGAACATCTCACACTTCTCT & 8 & 128 & 7 & 3.25 & 1.40 & 0.64 \\
\hline RM506 & CGAGCTAACTTCCGTTCTGG & GCTACTTGGGTAGCTGACCG & 8 & 128 & 4 & 2.65 & 1.08 & 0.55 \\
\hline RM219 & CGTCGGATGATGTAAAGCCT & CATATCGGCATTCGCCTG & 9 & 128 & 4 & 2.60 & 1.13 & 0.56 \\
\hline RM278 & GTAGTGAGCCTAACAATAATC & TCAACTCAGCATCTCTGTCC & 9 & 128 & 3 & 1.73 & 0.75 & 0.38 \\
\hline RM7217 & TTTGTAGGATGACACGTGGC & CGGGATTTCAGTACCTCACG & 10 & 128 & 8 & 3.89 & 1.57 & 0.70 \\
\hline RM216 & GCATGGCCGATGGTAAAG & TGTATAAAACCACACGGCCA & 10 & 128 & 4 & 1.39 & 0.55 & 0.26 \\
\hline RM224 & ATCGATCGATCTTCACGAGG & TGCTATAAAAGGCATTCGGG & 11 & 128 & 7 & 3.67 & 1.55 & 0.69 \\
\hline RM209 & ATATGAGTTGCTGTCGTGCG & СААСТTGСАТССТССССТСС & 11 & 128 & 5 & 2.60 & 1.22 & 0.58 \\
\hline RM17 & TGCCCTGTTATTTTCTTCTCTC & GGTGATCCTTTCCCATTTCA & 12 & 128 & 2 & 1.30 & 0.39 & 0.20 \\
\hline RM247 & TAGTGCCGATCGATGTAACG & CATATGGTTTTGACAAAGCG & 12 & 128 & 9 & 2.92 & 1.34 & 0.61 \\
\hline Total & - & - & - & - & 156 & 75.09 & - & - \\
\hline Mean & - & - & - & 256 & 6.50 & 3.13 & 1.26 & 0.58 \\
\hline Variance & - & - & - & - & 4.32 & 1.29 & 0.46 & 0.17 \\
\hline
\end{tabular}




\section{The potential of landraces in breeding}

The selection of parent materials in hybrid breeding is also dependent on the gene diversity in the parental gene bank. Narrow genomic information is not conducive to the selection of targeted traits (He et al., 2020). The results showed that genetic diversity of Changmaogu was also higher than those of Nipponbare, one of the main parental sources of hybrid rice (Table 3 ). The great genetic diversity of landrace can be used as an important supplement to the genetic diversity of parental gene bank in breeding (Kobayashi et al., 2006; Cui et al., 2015). Moreover, within a certain range, the further genetic relationship is, the greater the genetic difference is, the more favorable the concentration of benificial traits will be, and the stronger the heterosis of the offspring will be (Li, 2010). The results showed that Hejing 16 and Nipponbare have less differentiation, while landrace Changmaogu have greater differentiation to compare with Hejing 16 and Nipponbare populations (Figure 5). In terms of genetic differences, landrace also has considerable breeding potential in future breeding work.

\section{Factors affecting the genetic diversity of Changmaogu}

Different altitudes, temperatures and agro-ecological environments can directly or indirectly affect the richness of crop allelic resources (Demissie et al., 1997; Pagnotta et al., 2005). The altitude of Changmaogu planting area is $1800 \sim 2600 \mathrm{~m}$, and the annual average temperature is between $6-21^{\circ} \mathrm{C}$ (Table 4). Compared with the other two varieties, the cold environment at high altitude may lead to the accumulation of cold resistance genes in Changmaogu. In addition, the microbial community of mountain ecosystem affected by many factors, such as temperature, altitude gradient, climate change, soil characteristics, etc., has unique characteristics and diversity (Jaggi et al., 2020), leading to the accumulation of rice blast resistant gene resources in Changmaogu.

\section{The influence of commercialization}

After understanding the importance of landrace, the way to protect the genetic resource effectively becomes a focal issue. Because of hybrid rice's characteristics of high yield and high returns (Virk et al., 2003), farmers tend to choose the most profitable planting in order to maintain their families' livelihood, namely, to plant more hybrid cultivars with higher yield and greater benefits on fertile land, and only to plant more stress resistant varieties such as Changmaogu on poor land, or to give up the cultivation of landrace directly based on the consideration of economic efficiency of investment and return, leading to the substitution of landrace and the reduction of genetic diversity (Virk et al., 2007; Luo et al., 2019). It was reported that a hybrid cultivar (PN3) in Tanzania replaced $75-90 \%$ of the landrace planting area in the second year after its first introduction into local villages for its high yield, high maturity and superior quality to landrace (Friishansen et al., 2000). More and more widely used hybrid cultivars are seriously causing genetic erosion of the genetic bank (Frankel et al., 1982). The conservation of landraces with rich genetic diversity is becoming increasingly urgent.

In recent years, with the increasing popularity of ecological agricultural products, the demand for landraces has increased. However, due to the limitations of farmers' activity areas, it is difficult for the excellent local ecological agricultural products to be further promoted to the areas with higher demand. Therefore, it is worth thinking about a protection measure to establish a company with the integrated operation mode of 'agriculture-processing-marketing' to increase the economic income of farmers planting landraces and stimulate the re-expansion of landrace planting. This operation mode of integrated production and marketing has broadened the sales channels and increased the possible economic benefits of landrace. On one hand, the development of ecological agriculture can bring new economic incentives to local communities and bring more benefits to farmers. On the other hand, it also forms the ecological friendly farming mode, which can maintain the genetic diversity of crops by using Changmaogu and other landraces through the way of in-situ or on-farm conservation.

The results showed that Changmaogu had higher genetic diversity than that of Hongxiangmi (Table 3 ). Therefore, it is more valuable than Hongxiangmi in the conservation of rice genetic diversity. The 'agriculture-processing-marketing' model has been used for more than ten years for Hongxiangmi, but it has been less than five years for Changmaogu. During 'agriculture-processing-marketing' model period, farmers and companies have been organizing together to conduct simple artificial selection for a long time, which means keeping more or only the seeds of the line with the highest yield for next year's planting. It is a reasonable conjecture that the low genetic diversity of Hongxiangmi may be caused by the process of artificial selection with high yield. In order to explore the effect of artificial intervention on the genetic diversity of landraces, the changes of genetic diversity of landraces under

Table 3. Diversity parameters of the four groups within Oryza sativa.

\begin{tabular}{lcccccc}
\hline Variety & $\begin{array}{c}\text { Number of alleles } \\
\text { per each primer } \\
(\mathrm{Na})\end{array}$ & $\begin{array}{c}\text { Numbers of effective } \\
\text { alleles per } \\
\text { each primer }(\mathrm{Ne})\end{array}$ & $\begin{array}{c}\text { Observation } \\
\text { heterozagosity } \\
(\mathbf{H o})\end{array}$ & $\begin{array}{c}\text { Expected } \\
\text { heterozygosity } \\
\text { (He) }\end{array}$ & $\begin{array}{c}\text { Shannon } \\
\text { index } \\
\text { (I) }\end{array}$ & Nei's index \\
Changmaogu & 4.58 & 2.40 & 0.10 & 0.42 & 0.83 & 0.42 \\
Hejing 16 & 1.13 & 1.09 & 0.08 & 0.04 & 0.06 & 0.04 \\
\hline Nipponbare & 1.17 & 1.09 & 0.08 & 0.05 & 0.07 & 0.05 \\
Hongxiangmi & 2.21 & 1.62 & 0.09 & 0.30 & 0.51 & 0.30 \\
\hline
\end{tabular}

Table 4. Environmental information of three rice cultivars.

\begin{tabular}{lccc} 
Variety & $\begin{array}{c}\text { Altitude above sea level } \\
(\mathrm{m})\end{array}$ & $\begin{array}{c}\text { Annual average } \\
\text { temperature }\left({ }^{\circ} \mathrm{C}\right)\end{array}$ & $\begin{array}{c}\text { Topographic } \\
\text { features }\end{array}$ \\
Changmaogu & $1800-2600$ & $6-21$ & High mountain terraces, large environmental gradient \\
Hejing 16 & $1800-2100$ & $13-23$ & Plateau flat, small environmental gradient \\
\hline Hongxiangmi & $80-120$ & $20-27$ & Plain, small environmental gradient \\
\hline
\end{tabular}


'agriculture-processing-marketing' mode should be continuously tracked. Moreover, local germplasm bank should also periodically recollect landraces to preserve their genetic diversity and integrity.

\section{Development of conservation strategy}

Recently, commercialization techniques were introduced into the cultivation area of Changmaogu by a local company and our research group. A participatory market chain analysis technique was used to examine power relations among actors (farmers, sellers, consumers), linkages and governance aspects. The process enabled a business model that ensured biological and cultural diversity of landraces in the Lama community is conserved and used through sharing benefits between local people and commercial parties. The business model enabled to save the rare rice landrace. However, higher productivity is still the pursuance of both farmers and the company. The local people selected seeds for next year from individual plants with high productivity only. It is not appropriate to protect the genetic diversity of Changmaogu.

We herewith propose an integrated strategy to conserve the genetic diversity of Changmaogu based on our research results revealed by SSR markers: i) Since there was rich genetic diversity in samples of Changmaogu, seeds collected from local community should not be limited those with higher productivity or larger grains. All accessions of Changmaogu seeds should be stored in different seed banks for long-term preservation, especially in provincial and national crop seed banks; ii) The local biophysical environments vary extensively. It is necessary for Changmaogu to be conserved on farm. Thus the genetic diversity will be sustained in local environments; iii) The local implementation of participatory plant breeding (PPB) (Wang et al., 2016) is also worthy of attention. PPB is a scientific breeding method that researchers and local farmers cooperate closely to realize the genetic improvement of landraces. This kind of cooperation can not only improve the breeding efficiency of landraces and speed up the popularization of new varieties, but also give the participating farmers the power to improve their knowledge level, further maintain the genetic diversity of crops, promote the sustainable development of agriculture and bring many benefits (He et al., 2020). The abundant genetic diversity within the population of Changmaogu means that it can adapt to barren land using less pesticides, fertilizers and other chemical reagents, which will cause consumers be more interested in obtaining the Changmaogu products at higher prices for food safety. Thus farmers' enthusiasm to grow Changmaogu landrace with rich genetic diversity will be stimulated and the landrace will be continued to develop sustainably and conserve in Lama communities.

The massive human activities and rapid changes in the past a few decades resulted in loss of countless landraces around the world. Such loss of genetic resources is irreversible. People are looking for appropriate approaches to conserve biodiversity including genetic diversity. The strategy proposed in the present paper may be adoptable for the conservation and sustainable development of other rare landraces.

\section{Conclusions}

Changmaogu had more abundant genetic diversity and further genetic distance compared with hybrid rice Hejing 16 and rice parent Nipponbare, which meant that Changmaogu could be very important in rice seed selection in adverse environments and the acquisition of breeding parents. The abundant alleles of Changmaogu may be affected by the large environmental gradient of high mountains, the cold weather and the complex microbial community. The result that the genetic diversity of Changmaogu was more abundant than Hongxiangmi showed commercialization may lead to a decline in genetic diversity of landrace. Development strategy proposed in the present paper will be helpful for conserving Changmaogu and its genetic diversity.

\section{References}

Agriculture Commission on Genetic Resources, 2013. Reviewing the roles of animal genetic resources and options for their conservation. UN Food and Agriculture Organization, Rome, Italy, pp 4-5.

Bellon M, Gotor E, Caracciolo F, 2014. Conserving landraces and improving livelihoods: how to assess the success of on-farm conservation projects? Int. J. Agr. Sustain. 13:167-82.

Brown A, 1978. Isozymes, plant population genetic structure and genetic conservation. Theor. Appl. Genet. 52:145-57.

Camacho-Villa TC, Maxted N, Scholten M, Ford-Lloyd B, 2005. Defining and identifying crop landraces. Plant Genet. Resour.C. 3:373-84.

Chen LH, Liang XH, Ke L, 2009. Supporting system for the onfarm conservation of upland rice local species based on villagers' decision making behaviors, a case study of the Jiangtou Manmi, Jinghong, Yunnan. Yunnan Geograp. Environ. Res. 21:7-15.

Cui D, 2015. Association mapping of stress tolerance in Japonica rice germplasm and diachronic analysis of genetic diversity in rice landraces under on-farm conservation in Yunnan, China. Degree Diss., Chinese Academy of Agricultural Sciences, China.

Cui D, Li JM, Tang CF, A XX, Yu TQ, Ma XD, Zhang E, Cao GL, Xu FR, Qiao YL, Dai LY, Han LZ, 2015. Diachronic analysis of genetic diversity in rice landraces under on-farm conservation in Yunnan, China. Theor. Appl. Genet. 129:155-68.

Dang XJ, Thi T, Edzesi W, Liang LJ, Liu QM, Liu E, Wang Y, Qiang S, Liu LL, Hong D, 2015. Population genetic structure of Oryza sativa in East and Southeast Asia and the discovery of elite alleles for grain traits. Sci. Rep.-UK. 5:11254.

Demissie A, Bjørnstad A, 1997. Geographical, altitude and agroecological differentiation of isozyme and hordein genotypes of landrace barleys from Ethiopia: implications to germplasm conservation. Genet. Resour. Crop Ev. 44:43-55.

Francis CY, Yang RC, Tim B, 2000. POPGENE32 (1.32). Available from: http://www.ualberta.ca/ fyeh/download.htm

Frankel OH, Soule ME, 1982. Conservation and evolution. Cambridge University Press, New York, NY, USA.

Friishansen E, Almekinders C, Boef WD, 2000. Farmers' management and use of crop genetic diversity in Tanzania. Intermediate Technology Publications, London, UK, pp 66-71.

Hartings H, Berardo N, Mazzinelli G, Valoti P, Verderio A, Motto M, 2008. Assessment of genetic diversity and relationships among maize (Zea mays L.) Italian landraces by morphological traits and AFLP profiling. Theor. Appl. Genet. 117:831-42.

He L, Song YJ, Long CL, 2020. Genetic diversity of rice landraces in Yuanyang Hani terraced rice fields under in-situ conservation: research progress. Chin. Agri. Sci. Bull. 36:87-94.

Hu GL, Zhang DL, Pan HQ, Li B, Wu JT, Zhou XY, Zhang QY, Zhou L, Yao GX, Li JZ, Li JJ, Zhang HL, 2011. Fine mapping of the awn gene on chromosome 4 in rice by association and linkage analyses. Chin. Sci. Bull. 56:835-9.

Jaggi V, Brindhaa NT, Sahgal M, 2020. Microbial diversity in north western Himalayan agroecosystems: microbial diversity in north western Himalayan agroecosystems: functions and 
applications. Rhizos. Biol. 135-61.

Jarvis D, Brown A, Pham Hung C, Collado-Panduro L, Latournerie L, Gyawali S, Tanto T, Mahamadou S, Mar I, Sadiki M, Hue N, Arias-Reyes L, Balma D, Bajracharya J, Castillo F, Rijal D, Belqadi L, Rana R, Saidi S, Hodgkin T, 2008. A global perspective of the richness and evenness of traditional crop-variety diversity maintained by farming community. Proc. Natl. Acad. Sci. U. S. A. 105:5326-31.

Jarvis D, Hodgkin T, Brown A, Tuxill J, Lopez-Noriega I, Smale M, Sthapit B, 2016. Crop Genetic Diversity in the Field and on the Farm. Yale University Press., New Haven \& London, UK.

Khan G, Shikari A, Vaishnavi R, Najeeb S, Padder BA, Bhat Z, Parray G, Bhat M, Kumar R, Singh N, 2018. Marker-assisted introgression of three dominant blast resistance genes into an aromatic rice cultivar Mushk Budji. Sci. Rep.-UK. 8:4091.

Kobayashi A, Ebana K, Fukuoka S, Nagamine T, 2006. Microsatellite markers revealed the genetic diversity of an old Japanese rice landrace 'Echizen'. Genet. Resour. Crop Ev. 53:499-506.

Li C, Zhang Y, Ying K, Liang XL, Han B, 2004. Sequence variations of simple sequence repeats on chromosome-4 in two subspecies of the Asian cultivated rice. Theor. Appl. Genet. 108:392-400.

Li YJ, 2010. A study on the advancement of hybrid rice technology in China (1964-2010). Degree Diss., Nanjing Agricultural University, China.

Li YL, Long CL, Kato KJ, Yang CY, Sato K, 2011. Indigenous knowledge and traditional conservation of hulless barley (Hordeum vulgare) germplasm resources in the Tibetan communities of Shangri-la, Yunnan, SW China. Genet. Resour. Crop Ev. 58:645-55.

Long CL, 2016. Can commercialization save rare landraces in small ethnic communities? in The 7th International Crop Science Congress (7th ICSC) China, Beijing, China.

Lopes M, El-Basyoni I, Baenziger P, Singh S, Royo C, Ozbek K, Aktas H, Özer E, Ozdemir F, Manickavelu A, Ban T, Vikram P, 2015. Exploiting genetic diversity from landraces in wheat breeding for adaptation to climate change. J. Exp. Bot. 66:3477-86.

Luo BS, Liu B, Zhang HZ, Zhang HK, Li X, Ma LJ, Wang YZ, Bai YJ, Zhang XB, Li JQ, Yang J, Long CL, 2019. Wild edible plants collected by Hani from terraced rice paddy agroecosystem in Honghe Prefecture, Yunnan, China. J. Ethnobiol. Ethnomed. 15:56.

Mitchell M. 2011. GeneMarker ${ }^{\circledR}$ HID: a reliable software tool for the analysis of forensic STR data. J. Forensic Sci. 56:29-35.

Morgante M, Olivieri AM, 1993. PCR-amplified microsatellites as markers in plant genetics. Plant J. 3:175-82.

Nagy S, Poczai P, Cernák I, Gorji AM, Hegedűs G, Taller J, 2012. PIC Calc: an online program to calculate polymorphic information content for molecular genetic studies. Biochem. Genet. 50:670-2.

Pagnotta MA, Impiglia A, Tanzarella OA, Nachit MM, Porceddu E, 2005. Genetic variation of the durum wheat landrace Haurani from different agro-ecological regions. Genet. Resour. Crop Ev. 51:863-9.

Pusadee T, Jamjod S, Chiang Y, Rerkasem B, Schaal B, 2009. Genetic structure and isolation by distance in a landrace of Thai rice. Proc. Natl. Acad. Sci. U. S. A. 106:13880-5.

Schlötterer C, Amos W, Tautz D, 1991. Conservation of polymorphic simple sequence loci in Cetacean species. Nature. 354:63-5.

Song YJ, Qiong F, Jarvis D, Bai K, Liu DM, Feng JC, Long CL, 2019. Network analysis of seed flow, a traditional method for conserving tartary buckwheat (Fagopyrum tataricum) landraces in Liangshan, Southwest China. Sustain.-Basel. 11:4263.

Sponenberg DP, 2014. Genetic resources and their conservation. In: The Genetics of the Horse (eds Bowling AT, Ruvinsky A). CABI Publishing, Wallingford, Oxfordshire, UK, pp 392-3.

Sudhir K, Glen S, Li M, Christina K, Koichiro T, 2018. MEGA X: molecular evolutionary genetics analysis across computing platforms. Mol. Biol. Evol. 35:1547-9.

Virk D, Singh DN, Prasad SC, Gangwar JS, Witcombe J, 2003. Collaborative and consultative participatory plant breeding of rice for the rainfed uplands of eastern India. Euphytica. 132:95-108.

Virk D, Witcombe J, 2007. Trade-offs between on-farm varietal diversity and highly client-oriented breeding - A case study of upland rice in India. Genet. Resour. Crop Ev. 54:823-35.

Wang XQ, Pang YL, Zhang J, Wu ZC, Chen K, Ali J, Ye GY, Xu JL, Li ZK, 2017. Genome-wide and gene-based association mapping for rice eating and cooking characteristics and protein content. Sci. Rep.-UK. 7:17203.

Wang YJ, Wang YL, Sun XD, Caiji ZM, Yang JB, Cui D, Cao GL, Ma XD, Han B, Xue DY, 2016. Influence of ethnic traditional cultures on genetic diversity of rice landraces under on-farm conservation in southwest China. J. Ethnobiol. Ethnomed. $12: 51$.

Williams J, Kubelik A, Livak K, Rafalski J, Tingey S, 1990. DNA polymorphisms amplified by arbitrary primers are useful as genetic markers. Nucleic Acids Res. 18:6531-5.

Xiang JT, 2012. An environmental anthropology study of red-rice of the Hani Yich piople in Langdi, Honghe County, Yunnan Province, China. Degree Diss., Yunnan University, China.

Yang GP, Maroof S, Xu C, Zhang Q, Biyashev R, 1994. Comparative analysis of microsatellite DNA polymorphism in landraces and cultivars of rice. Mol. Gen. Genet. 245:187-94.

Yang JB, Wang YC, Wang D, Guo L, 2018. Application of traditional knowledge of Hani people in biodiversity conservation. Sustain.-Basel. 10:4555.

Yang YH, Bai KY, Devra J, Long CL, 2019. Xishuangbanna cucumber landraces and associated traditional knowledge. Biodiv. Sci. 27:743-8.

Zeng YW, Li ZC, Yang ZY, Wang XK, Shen SQ, Zhang HL, Chen YM, 2000. Law and center of diversity of main characters of indigenous rice (Oryza sativa L.) in Yunnan. J. Huazhong Agri. Univ. 511-7.

Zeng YW, Wang JJ, Yang ZY, Shen SQ, Wu LH, Chen XY, Meng JG, 2001. The diversity and sustainable development of crop genetic resources in the Lancang River Valley. Genet. Resour. Crop Ev. 48:297-306.

Zeng YW, Zhang HL, Li ZC, Shen SQ, Wen GS, 2007. Evaluation of genetic diversity of rice landraces (Oryza sativa L.) in Yunnan, China. Breeding Sci. 57:91-9.

Zhang HL, Sun JL, Wang MX, Liao DQ, Zeng YW, Shen SQ, Yu P, Mu P, Wang XK, Li ZC, 2007. Genetic structure and phylogeography of rice landraces in Yunnan, China, revealed by SSR. Genome. 50:72-83.

Zhang YY, 2005. The analysis of genetic diversity for indica local rice from different place of China. Degree Diss., Chinese Academy of Agricultural Sciences, China.

Zhu MY, Wang YY, Zhu YY, Lu BR, 2004. Estimating genetic diversity of rice landraces from Yunnan by SSR assay and its implication for conservation. Acta Bot. Sin. 46:12. 